\title{
Qualidade da bebida de café de frutos cereja submetidos a diferentes manejos pós-colheita
}

\author{
José Laércio Favarin ${ }^{(1)}$, André Luis Gnaccarini Villela(1), Maria Heloisa Duarte Moraes ${ }^{(2)}$, \\ Helena Maria Carmignani Pescarin Chamma ${ }^{(1)}$, José Dias Costa ${ }^{(1)}$ e Durval Dourado-Neto ${ }^{(3)}$
}

\begin{abstract}
(1)Escola Superior de Agricultura Luiz de Queiroz (Esalq), Dep. de Produção Vegetal, Caixa Postal 9, CEP 13418-900 Piracicaba, SP. E-mail: jlfavari@esalq.usp.br, andre.villela@syngenta.com.br, hmcpcham@esalq.usp.br, eemcosta@esalq.usp.br, (2)Esalq, Dep. de Entomologia, Fitopatologia e Zoologia Agrícola. E-mail: mhdmorae@esalq.usp.br ${ }^{(3)}$ Esalq, Dep. de Produção Vegetal. Bolsista do CNPq. E-mail: dourado@esalq.usp.br
\end{abstract}

Resumo - O objetivo deste trabalho foi avaliar a qualidade da bebida de café obtida de frutos cereja submetidos a diferentes práticas de manejo pós-colheita, considerando-se infecções iniciadas na planta e persistentes durante o tempo de exposição às fontes infectantes. Admitiu-se que os grãos de cereja recolhidos na planta têm máximo potencial de qualidade da bebida, avaliada por meio de testes rápidos e análise sensorial. Foram adotados oito tratamentos, formados pela combinação de quatro manejos pós-colheita e frutos de café com e sem desinfecção por cloreto de benzalcônio. A qualidade da bebida de grãos de frutos cereja não foi prejudicada pelo manejo pós-colheita, mesmo sob exposição às infecções por até 12 horas após a derriça. Os testes rápidos não se correlacionaram com a análise sensorial da bebida, e o teste da condutividade elétrica foi mais sensível que o da lixiviação de potássio. Ambos indicaram alterações nos grãos de frutos expostos às infecções após seis horas da colheita. A desinfecção superficial dos frutos foi eficiente até a primeira hora após a imersão, diminuindo o número de frutos infectados por Cladosporium sp., Penicillum sp. e Alternaria sp.

Termos para indexação: Coffea arabica, condutividade elétrica, lixiviação de potássio, análise sensorial, controle de qualidade.

\section{Quality of coffee drink from fruits submitted to different post-harvest management practices}

\begin{abstract}
The objective of this work was to evaluate the quality of the coffee drink from fruits with different postharvest management practices, considering the initial plant disease infection and during the coffee fruit exposition period. The following basic assumptions were defined: the harvested grain from the plant has higher coffee fruit drink potential quality, and the quality can be evaluated using fast tests and sensorial analysis. Eight treatments were established based on the post-harvest management with and without benzalcone chloride disinfection. The coffee fruit drink quality was not affected by the post-harvest management, including the treatment with 12 hours grain exposition after harvest. The fast tests were not correlated with the coffee drink sensorial analysis. The electric conductivity test was more sensitive than the potassium lixiviation test, and the grain modification occurred after six hours of fruit exposition. The efficiency of fruit superficial disinfection was verified during the first hour after immersion, decreasing the number of fruits infected by Cladosporium sp., Penicillum sp. and Alternaria sp.

Index terms: Coffea arabica, electric conductivity, potassium lixiviation, sensory evaluation, quality controls.
\end{abstract}

\section{Introdução}

A demanda por café diferenciado intensificou-se a partir da década de 90, criando novas oportunidades e estimulando a relação entre o cafeicultor e o cliente (Caixeta, 1998).

A fim de obter café de qualidade superior, os cuidados com a colheita e o manejo pós-colheita tornaram-se fundamentais na comercialização e no aumento do lucro do cafeicultor.

A qualidade da bebida de café depende da composi- ção química do grão, determinada por fatores genéticos, tratos culturais e características do ambiente de cultivo (Carvalho \& Chalfoun, 1985). De acordo com Cortez (2001), é indispensável que o café colhido seja preparado e submetido em seguida à secagem para evitar o desenvolvimento de processos fermentativos e prejuízos à qualidade da bebida. Sob esse aspecto, é fundamental o manejo pós-colheita, em particular, o tempo de exposição aos microrganismos, os quais iniciam a infecção na planta e persistem após a colheita, até mesmo em parte do período de secagem. 
As características da bebida de café são influenciadas por modificações nos grãos atribuídas a distúrbios fisiológicos e às fermentações microbianas que degradam os açúcares da mucilagem dos frutos na planta, formando álcoois ou ácidos carboxílicos (Krug, 1940a, 1940b). Segundo o autor, há relação entre o ataque de fungos e bactérias e a qualidade final da bebida.

O processo fermentativo pela ação de microrganismos, como bactérias, bolores e leveduras, deteriora as membranas dos grãos (Amorim \& Amorim, 1977; Jones \& Jones, 1984). Entretanto, se o fenômeno é interrompido após a perda da camada mucilaginosa do fruto, o endosperma não é comprometido e a qualidade da bebida é preservada. A continuidade do processo implica quebra das paredes e membranas celulares, degradação de camadas celulares e alteração de compostos químicos dos grãos e da bebida, resultando em sabor e odor desagradáveis (Dentan, 1988, 1989a, 1989b, 1992; Vanos, 1988).

Durante a maturação da semente, ocorrem várias transformações morfológicas, fisiológicas, bioquímicas e funcionais (Popinigis, 1977; Marcos Filho et al., 1982), em que as membranas celulares são as últimas que se organizam e as primeiras que apresentam sinais de deterioração após a maturidade fisiológica (Heydecker, 1974).

Vários trabalhos evidenciaram a existência de relação entre a desorganização das membranas celulares e a perda de constituintes dos grãos, com o aumento da quantidade de exsudatos determinados na água de embebição (Woodstock, 1973; Schoettle \& Leopold, 1984; Lin, 1988; Marcos Filho et al., 1990; Prete, 1992).

Com base na hipótese de Amorim (1978) de que a perda da permeabilidade e as alterações nas estruturas das membranas celulares sejam responsáveis pela deterioração do café, Prete (1992) verificou uma relação inversa entre a qualidade da bebida e a condutividade elétrica e a lixiviação de $\mathrm{K}$, determinadas no exsudato de grãos crus.

Assim, os testes rápidos, como de condutividade elétrica e de lixiviação de K, poderiam auxiliar o cafeicultor na separação de lotes, enquanto não se dispõe dos resultados da análise sensorial (padrão), de natureza subjetiva, expressa pelo aroma e sabor, efetuada por profissional do ramo.

O objetivo deste trabalho foi avaliar a qualidade potencial da bebida de café obtida de grãos de frutos cereja submetidos a diferentes práticas de manejo pós-colheita, considerando-se infecções iniciadas na planta e persistentes durante o tempo de exposição às fontes infectantes.

\section{Material e Métodos}

Foram utilizadas amostras de café de uma lavoura da Fazenda Nova Java, localizada em Piracicaba, SP, com latitude de $22^{\circ} 43^{\prime} 30^{\prime \prime} \mathrm{S}$, longitude de $47^{\circ} 38^{\prime} 0^{\prime \prime}$ W e altitude de $540 \mathrm{~m}$. De acordo com a classificação de Köppen, o clima regional é do tipo Cwa, tropical de altitude com inverno seco. O cafezal da cultivar Catuaí Amarelo IAC 62, com 48 meses de idade, está localizado nas proximidades de uma represa, fato que, aliado às condições climáticas locais e à baixa altitude, pode afetar a qualidade da bebida do café.

O delineamento experimental adotado foi inteiramente casualizado, com quatro repetições, em esquema fatorial $4 \times 2$ (quatro manejos pós-colheita e frutos de café cereja tratados e não tratados com cloreto de benzalcônio), totalizando oito tratamentos. A população controle foi representada pela amostra de frutos cereja recolhida diretamente na planta, infectada naturalmente, com e sem desinfecção, respectivamente, T1 e T2. Os demais tratamentos foram: frutos cereja recolhidos da mistura de frutos no pano, uma hora após a derriça, com e sem desinfecção, respectivamente, T3 e T4; frutos cereja recolhidos da mistura de frutos ensacados, seis horas após a derriça, com e sem desinfecção, respectivamente, T5 e T6; frutos cereja recolhidos da mistura de frutos amontoados, 12 horas após a derriça, com e sem desinfecção, respectivamente, T7 e T8.

A desinfecção por cloreto de benzalcônio foi realizada superficialmente, durante 10 minutos, por meio da imersão dos frutos em solução a 5\% de Fegatex (cloreto de benzalcônio) antes da separação das amostras para a análise microbiológica e o início da secagem.

Para a detecção de fungos nas amostras com e sem desinfecção, foram separadas quatro subamostras de 50 frutos de cada repetição e colocadas em caixas de plástico contendo três folhas de papel-filtro umedecidas em água destilada. As caixas foram deixadas em câmara de incubação com temperatura de $20 \pm 2^{\circ} \mathrm{C}$ e luz branca fluorescente alternada (12 horas de luz/12 horas escuro) durante sete dias (Lucca Filho, 1987). A seguir, avaliou-se a incidência de fungos nos frutos com auxílio de microscópio estereoscópico e microscópio composto, e os resultados foram expressos em números de frutos contaminados.

As amostras de frutos de cada tratamento, com e sem desinfecção superficial, foram secadas em bandejas de plástico, revestidas internamente com papel-filtro branco, 
mantidas em balcão a 0,6 m da superfície do solo, em ambiente coberto com telha transparente para a proteção das chuvas e da umidade noturna. Durante o dia os frutos (cereja) foram, periodicamente, movimentados para a uniformização da secagem, evitando o aquecimento.

Antes de finalizar a secagem, foram separadas quatro subamostras de cada parcela (repetição) para a determinação do teor de água pelo método da secagem em estufa a $105 \pm 3^{\circ} \mathrm{C}$ durante 24 horas, de acordo com as Regras para Análise de Sementes (Brasil, 1992), visando à uniformidade da umidade dos grãos.

$\mathrm{Na}$ seqüência, os frutos foram beneficiados para a retirada da casca e classificados por tamanho, utilizando peneiras de crivos redondos. As frações de grãos crus de café da peneira 18 (18/64"), classe predominante, foram utilizadas na determinação da condutividade elétrica de acordo com o método proposto pelo Comitê de Vigor da Association of Official Seed Analysts (1983). Foram utilizadas quatro subamostras de 25 grãos crus, sem defeitos aparentes, por repetição, as quais, após a determinação da massa, foram imersas em $75 \mathrm{~mL}$ de água destilada durante 3,5 horas a $20^{\circ} \mathrm{C}$ (Prete, 1992). Em seguida, realizou-se a leitura da condutividade elétrica nos exsudatos de grãos crus em aparelho DIGIMED CD-20. Na seqüência, verteu-se a solução contendo exsudatos de grãos crus em recipientes de vidro, dos quais retiraram-se alíquotas para a determinação da quantidade de $\mathrm{K}$ lixiviado em fotômetro de chama DIGIMED NK-2004, conforme Prete (1992).

As amostras de grãos da peneira 18 de cada tratamento, com e sem desinfecção por cloreto de benzalcônio, foram avaliadas por meio da análise sensorial e classificação da bebida (prova de xícara), método adotado como referência na comparação com os resultados determinados pelos testes rápidos (condutividade elétrica e lixiviação de K). Esse procedimento foi realizado por provador-clas- sificador, de acordo com as Normas de Classificação Comercial por Tipos e Bebidas (Instituto Brasileiro do Café, 1985; Toledo \& Barbosa, 1998). As características e intensidades de gosto, assim como as sensações bucais e sabores e aromas predominantes na bebida, seguiram as descrições da Organização Internacional do Café (FeriaMorales, 1989; Cortez, 1996), atribuindo-se notas pelo provador-classificador em escala crescente de aceitação de 0 a 5 (Cortez, 1996).

Os resultados do número de frutos infectados, após a transformação dos dados pela função $(x+0,5)^{0,5}$ da condutividade elétrica e lixiviação de $\mathrm{K}$, foram submetidos à análise de variância. Ao ser constatada a significância pelo teste $\mathrm{F}$, comparam-se os tratamentos por meio do teste de Tukey a $1 \%$ de probabilidade (Banzatto \& Kronka, 1995).

\section{Resultados e Discussão}

A desinfecção antes da secagem foi eficiente na diminuição do número de frutos infectados por Cladosporium sp. nas amostras de frutos cereja recolhidas na planta do tratamento T1 e nas amostras de cereja recolhidas da mistura de frutos derriçados no pano, uma hora após a colheita, tratamento T3 (Tabela 1). Nos tratamentos nos quais os frutos permaneceram por mais tempo infectados e em contato com as fontes de contaminação (frutos deteriorados, passas e secos), a desinfecção não foi eficiente, conforme os resultados do grau de infecção das amostras de cerejas recolhidas da mistura de frutos ensacados, durante seis horas após a derriça, tratamentos T5 e T6, e de cerejas recolhidas da mistura de frutos amontoados no terreiro, 12 horas após a derriça, nos tratamentos T7 e T8

A desinfecção também reduziu o número de frutos infectados por Penicillium sp. nas amostras de cerejas

Tabela 1. Número de frutos infectados em amostras de cerejas com (CD) e sem (SD) a desinfecção superficial por cloreto de benzalcônio, em razão do manejo pós-colheita ${ }^{(1)}$.

\begin{tabular}{|c|c|c|c|c|c|c|c|c|c|c|}
\hline \multirow[t]{2}{*}{ Tratamento } & \multicolumn{2}{|c|}{ Cladosporium sp. } & \multicolumn{2}{|c|}{ Penicillum sp. } & \multicolumn{2}{|c|}{ Alternaria sp. } & \multicolumn{2}{|c|}{ Colletotrichum sp. } & \multicolumn{2}{|c|}{ Epicoccum sp. } \\
\hline & $\mathrm{CD}$ & SD & $\mathrm{CD}$ & SD & $\mathrm{CD}$ & SD & $C D$ & $\mathrm{SD}$ & $\mathrm{CD}$ & SD \\
\hline $\mathrm{T} 1$ e $\mathrm{T} 2$ & $24,5 \mathrm{cB}$ & $50,0 \mathrm{aA}$ & $0,1 \mathrm{bB}$ & $2,9 \mathrm{abA}$ & $6,2 \mathrm{cA}$ & $1,4 \mathrm{bB}$ & $29,8 \mathrm{bA}$ & $0,0 \mathrm{aB}$ & $0,1 \mathrm{aA}$ & $0,4 \mathrm{bA}$ \\
\hline $\mathrm{T} 3$ e $\mathrm{T} 4$ & $39,7 \mathrm{bB}$ & $50,0 \mathrm{aA}$ & $0,6 \mathrm{bA}$ & $0,4 \mathrm{bA}$ & $18,1 \mathrm{bA}$ & $1,7 \mathrm{bB}$ & $40,5 \mathrm{aA}$ & $0,0 \mathrm{aB}$ & $0,2 \mathrm{aB}$ & $2,9 \mathrm{abA}$ \\
\hline T5 e T6 & $47,4 \mathrm{aA}$ & $50,0 \mathrm{aA}$ & $3,9 \mathrm{aA}$ & $5,6 \mathrm{aA}$ & $24,1 \mathrm{bA}$ & $28,4 \mathrm{aA}$ & $15,0 \mathrm{cA}$ & $0,0 \mathrm{aB}$ & $0,7 \mathrm{aB}$ & $5,8 \mathrm{aA}$ \\
\hline $\mathrm{T} 7$ e $\mathrm{T} 8$ & $50,0 \mathrm{aA}$ & $50,0 \mathrm{aA}$ & $0,6 \mathrm{bA}$ & $0,2 \mathrm{bA}$ & $41,4 \mathrm{aA}$ & $39,9 \mathrm{aA}$ & $1,5 \mathrm{dA}$ & $0,0 \mathrm{aB}$ & $1,8 \mathrm{aA}$ & $1,7 \mathrm{abA}$ \\
\hline
\end{tabular}

(1)Médias seguidas pelas mesmas letras, minúsculas nas colunas e maiúsculas nas linhas, não diferem entre si pelo teste de Tukey a $1 \%$ de probabilidade; T1 e T2: frutos cereja recolhidos na planta, infectados naturalmente, com e sem desinfecção, respectivamente; T3 e T4: frutos cereja recolhidos da mistura de frutos no pano, uma hora após a derriça, com e sem desinfecção, respectivamente; T5 e T6: frutos cereja recolhidos da mistura de frutos ensacados, seis horas após a derriça, com e sem desinfecção, respectivamente; T7 e T8: frutos cereja recolhidos da mistura de frutos amontoados, 12 horas após a derriça, com e sem desinfecção, respectivamente. 
selecionadas na planta, tratamento T1, enquanto nas amostras dos tratamentos T3, T5 e T7 não houve mudanças no grau de infecção pela utilização de cloreto de benzalcônio (Tabela 1).

Com relação ao fungo Alternaria sp., o grau de infecção foi superior nas amostras de cerejas tratadas com cloreto de benzalcônio nos menores tempos de exposição às infecções, tratamentos T1 e T3 (Tabela 1), indicando que o desinfetante foi ineficiente no controle desses fungos. O número de frutos infectados aumentou após uma hora de exposição às infecções.

O nível de frutos infectados por Colletotrichum sp. também não foi afetado pela desinfecção com cloreto de benzalcônio, uma vez que as maiores quantidades de frutos com esses fungos foram verificadas nas amostras tratadas, principalmente nos tratamentos T1, T3 e T5 (Tabela 1), diminuindo no tratamento T7 devido ao aumento da população de Alternaria sp., provavelmente, pela competição entre esses fungos. A ausência de frutos infectados por Colletotrichum sp., independentemente do tempo de contato e exposição às infecções nas amostras sem desinfecção nos tratamentos T2, T4, T6 e T8, pode ser explicada pelo antagonismo com os gêneros Cladosporium e Alternaria. Essa constatação é reforçada pela diminuição do número de frutos infectados por Colletotrichum sp. nos tratamentos T5 e T7 com desinfecção, em que se detectou perda de eficiência da desinfecção no controle de Cladosporium sp. e de Alternaria sp., principalmente, no tratamento T7.

O grau de infecção por fungos do gênero Epicoccum sp. reduziu-se significativamente nas amostras de cerejas recolhidas de frutos uma hora após a derriça, tratamento $\mathrm{T} 3$, e daqueles que permaneceram ensacados por até seis horas após a derriça, tratamento T5, em relação a não desinfecção com cloreto de benzalcônio, como se verificou nos tratamentos T4 e T6, respectivamente (Tabela 1).

Os gêneros Epicoccum e Cladosporium ocorrem comumente em frutos do cafeeiro e não se desenvol- vem durante a secagem no terreiro (Bitancourt, 1957), o que explica a presença de ambos nas amostras de frutos cereja, uma vez que as análises microbiológicas foram efetuadas antes da secagem.

Bitancourt (1957) constatou que o gênero Colletotrichum e bolores verdes do gênero Penicillium, entre outros, são fungos abundantes nas diferentes fases do preparo do café, ocorrendo no próprio cafeeiro e também no terreiro de secagem. O defeito preto é, em alguns casos, atribuído à infecção por Colletotrichum sp., provocando a morte do embrião (Cortez, 1997). O grau de infecção por Colletotrichum sp. constatado nos frutos cereja dos tratamentos T1 e T3 (Tabela 1), no período de avaliação do experimento, não alterou a bebida (Tabela 2), independentemente dos tratamentos, assim como não provocou alteração nos grãos que pudesse ser detectada por meio dos testes rápidos nos tratamentos T1 e T3 (Tabela 3). A presença de fungos do gênero Alternaria contaminando a maioria dos frutos, como ocorreu nos tratamentos T5, T6, T7 e T8, também não afetou a bebida, de acordo com a classificação sensorial realizada nos mesmos tratamentos (Tabela 2).

A avaliação sensorial e as notas de aceitação emitidas por provador-classificador (Tabela 2) evidenciam que as elevadas infecções pelos fungos Cladosporium sp. (todos os tratamentos), Alternaria sp. nos tratamentos T5, T6, T7 e T8 com e sem desinfecção, e Colletotrichum sp. nos tratamentos T1 e T3 com desinfecção, não influenciaram a qualidade da bebida, corroborando os resultados obtidos por Alves (1996). Pode-se afirmar que, considerando os valores da classificação por meio da prova sensorial (Tabela 2), a ação desses fungos, no período experimental, não provocou alterações suficientes que prejudicassem a qualidade da bebida.

De acordo com os resultados da classificação sensorial (Tabela 2) e dos testes rápidos de condutividade elétrica e lixiviação de K (Tabela 3), não foi constatada relação entre ambos, independentemente dos tratamentos, pois a classificação da bebida não se modificou como

Tabela 2. Classificação sensorial e notas de aceitação da bebida, emitida por provador-classificador, em amostras de grãos de frutos cereja com e sem a desinfecção superficial por cloreto de benzalcônio, em razão do manejo pós-colheita ${ }^{(1)}$.

\begin{tabular}{|c|c|c|c|c|c|}
\hline \multicolumn{3}{|c|}{ Com desinfecção } & \multicolumn{3}{|c|}{ Sem desinfecção } \\
\hline Tratamento & Classificação & Aceitação & Tratamento & Classificação & Aceitação \\
\hline T1 & Apenas mole/mole & $4,0 / 4,5$ & $\mathrm{~T} 2$ & Dura/apenas mole & $3,0 / 3,0$ \\
\hline T3 & Apenas mole/mole & $4,0 / 4,5$ & T4 & Apenas mole/apenas mole & $3,0 / 3,0$ \\
\hline T5 & Apenas mole/apenas mole & $4,0 / 3,5$ & T6 & Apenas mole/apenas mole & $3,5 / 4,0$ \\
\hline $\mathrm{T} 7$ & Mole/apenas mole & $4,0 / 4,0$ & $\mathrm{~T} 8$ & Apenas mole/mole & $4,5 / 4,0$ \\
\hline
\end{tabular}

${ }^{(1)}$ T1 e T2: frutos cereja recolhidos na planta, infectados naturalmente, com e sem desinfecção, respectivamente; T3 e T4: frutos cereja recolhidos da mistura de frutos no pano, uma hora após a derriça, com e sem desinfecção, respectivamente; T5 e T6: frutos cereja recolhidos da mistura de frutos ensacados, seis horas após a derriça, com e sem desinfecção, respectivamente; T7 e T8: frutos cereja recolhidos da mistura de frutos amontoados, 12 horas após a derriça, com e sem desinfecção, respectivamente. 
Tabela 3. Condutividade elétrica $\left(\mu \mathrm{S} \mathrm{m}^{-1} \mathrm{~g}^{-1}\right)$ e lixiviação de potássio $\left(\mathrm{mg} \mathrm{kg}^{-1}\right)$ em exsudatos de grãos de frutos cereja com e sem a desinfecção superficial por cloreto de benzalcônio, em razão do manejo pós-colheita ${ }^{(1)}$.

\begin{tabular}{|c|c|c|c|c|c|}
\hline \multicolumn{3}{|c|}{ Com desinfecção } & \multicolumn{3}{|c|}{ Sem desinfecção } \\
\hline Tratamento & Condutividade elétrica & Lixiviação de potássio & Tratamento & Condutividade elétrica & Lixiviação de potássio \\
\hline $\mathrm{T} 1$ & $123,10 \mathrm{bB}$ & $1.055,11 \mathrm{bB}$ & $\mathrm{T} 2$ & $168,19 \mathrm{cA}$ & $1.427,40 \mathrm{bA}$ \\
\hline $\mathrm{T} 3$ & $126,70 \mathrm{bB}$ & $1.116,12 \mathrm{bB}$ & $\mathrm{T} 4$ & $190,50 \mathrm{bA}$ & $1.459,90 \mathrm{bA}$ \\
\hline T5 & $162,28 \mathrm{aB}$ & $1.354,14 \mathrm{aB}$ & T6 & 197,21abA & $1.509,54 \mathrm{abA}$ \\
\hline $\mathrm{T} 7$ & $167,11 \mathrm{aB}$ & $1.422,26 \mathrm{aB}$ & $\mathrm{T} 8$ & $205,74 \mathrm{aA}$ & $1.613,45 \mathrm{aA}$ \\
\hline
\end{tabular}

(1) Médias seguidas pelas mesmas letras, minúsculas nas colunas e maiúsculas nas linhas, não diferem entre si pelo teste de Tukey a $1 \%$ de probabilidade; T1 e T2: frutos cereja recolhidos na planta, infectados naturalmente, com e sem desinfecção, respectivamente; T3 e T4: frutos cereja recolhidos da mistura de frutos no pano, uma hora após a derriça, com e sem desinfecção, respectivamente; T5 e T6: frutos cereja recolhidos da mistura de frutos ensacados, seis horas após a derriça, com e sem desinfecção, respectivamente; T7 e T8: frutos cereja recolhidos da mistura de frutos amontoados, 12 horas após a derriça, com e sem desinfecção, respectivamente.

ocorreu com os resultados dos testes rápidos, não confirmando, portanto, a correlação verificada por Prete (1992).

Os valores obtidos em relação à condutividade elétrica em grãos crus de café originados de cerejas recolhidas na planta, antes da derriça, classificadas como apenas mole/mole (T1: $123,10 \mu \mathrm{S} \mathrm{cm}^{-1} \mathrm{~g}^{-1}$ ) e dura/apenas mole (T2: $168,19 \mu \mathrm{S} \mathrm{cm}^{-1} \mathrm{~g}^{-1}$ ) (Tabela 2), não corroboram as observações de Prete (1992), que verificou, em grãos de bebidas mole/apenas mole, valores

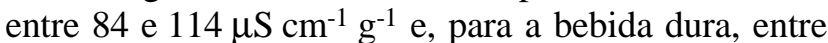
119 e $129 \mu \mathrm{S} \mathrm{cm}^{-1} \mathrm{~g}^{-1}$. Também observou a existência de relação entre a condutividade elétrica e a qualidade da bebida (análise sensorial). Os valores da condutividade elétrica verificados por Prete (1992), são, portanto, inferiores às medidas detectadas neste trabalho, que utilizou somente amostras de cerejas recolhidas na planta (T1 e T2: assumidas como máximo potencial para a qualidade da bebida). A diferença de resultados, assim como a interpolação entre as classes de condutividade elétrica para uma mesma bebida, verificada no trabalho de Prete (1992), indica que muitos fatores podem influenciar os resultados da condutividade elétrica.

Os resultados dos testes de condutividade elétrica e lixiviação de $\mathrm{K}$ foram influenciados pela desinfecção, sendo menores quando as amostras foram tratadas com cloreto de benzalcônio antes da secagem (Tabela 3). O tempo de infecção pelos microrganismos nas amostras sem desinfecção provocou aumentos nas medidas da condutividade elétrica a partir de uma hora após a colheita no tratamento $\mathrm{T} 4$, ao passo que nas amostras com desinfecção houve aumentos depois de seis horas após a colheita, no tratamento T5. Em condições semelhantes, o aumento na lixiviação de $\mathrm{K}$ foi detectado somente em amostras de cerejas recolhidas de uma mistura de frutos ensacados durante seis horas após a derriça, tratamentos T5 e T6, independentemente da desinfecção das amostras. Portanto, o teste da condutividade elétrica, com a finalidade de trabalhos dessa natureza, pela fácil operacionalidade e por ser realizável na propriedade, merece novos estudos com o intuito de orientar o manejo de lotes e atividades inerentes ao preparo do café, após a sua calibração às condições climáticas, cultivar e época de colheita.

A desinfecção com cloreto de benzalcônio reduziu sensivelmente as medidas da condutividade elétrica nas amostras de cerejas recolhidas de uma mistura de frutos amontoados no terreiro 12 horas após a derriça (T7: $167,11 \mu \mathrm{S} \mathrm{cm}^{-1} \mathrm{~g}^{-1}$ ), cujo resultado foi semelhante ao obtido em amostras de cerejas recolhidas na planta sem desinfecção (T2: 168,19 $\mu \mathrm{S} \mathrm{cm}^{-1} \mathrm{~g}^{-1}$ ) (Tabela 3).

\section{Conclusões}

1. A qualidade da bebida de café obtida de grãos de frutos cereja não é prejudicada pelo manejo pós-colheita com exposição às infecções por até 12 horas após a derriça.

2. A desinfecção superficial dos frutos por cloreto de benzalcônio é eficiente até a primeira hora após a imersão; diminui o número de frutos infectados por Cladosporium sp., Penicillum sp. e Alternaria sp.

3. Os testes rápidos não se correlacionam com a análise sensorial da bebida (padrão), e o teste da condutividade elétrica é mais sensível que o da lixiviação de potássio; ambos indicam alterações nos grãos de frutos expostos às infecções após seis horas da colheita.

\section{Referências}

ALVES E. População fúngica associada ao café (Coffea arabica $\mathbf{L}$.) beneficiado e às fases de pré e pós colheita: relações com a bebida e local de cultivo. 1996. 49p. Dissertação (Mestrado) - Universidade Federal de Lavras, Lavras. 
AMORIM, H.V. Aspectos bioquímicos e histoquímicos do grão de café verde relacionados com a deterioração da qualidade. 1978. 85p. Tese (Livre-Docência) - Escola Superior de Agricultura Luiz de Queiroz, Piracicaba.

AMORIM, H.V.; AMORIM, V.L. Coffee enzymes and coffee quality. In: ORY, R.L.; ST. ANGELO, A.J. (Ed.). Enzymes in food and beverage processing. Washington: American Chemical Society, 1977, p.27-56. (Symposium Series, 47).

ASSOCIATION OF OFFICIAL SEED ANALYSTS (Las Cruces, Estados Unidos). Seed vigor testing handbook. East Lasing, 1983. 93p. (Contribution, 32).

BANZATTO, D.A.; KRONKA, S. do N. Experimentação agrícola. Jaboticabal: Funep, 1995. 247p.

BITANCOURT, A.A. O tratamento das cerejas de café para melhorar a bebida. O Biológico, v.23, p.1-11, 1957.

BRASIL. Ministério da Agricultura e Reforma Agrária. Regras para análise de sementes. Brasília: Departamento Nacional de Defesa Vegetal, 1992. 365p.

CAIXETA, G.Z.T. Comportamento atual do mercado de café. Informe Agropecuário, v.19, p.9-13, 1998.

CARVALHO, V.D.; CHALFOUN, S.M. Aspectos qualitativos do café. Informe Agropecuário, v.11, p.79-92, 1985.

CORTEZ, J.G. Aptidão climática para a qualidade da bebida nas principais regiões cafeeiras de Minas Gerais. Informe Agropecuário, v.18, p.27-31, 1997.

CORTEZ, J.G. Efeito de espécies e cultivares e do processamento agrícola e industrial nas características da bebida do café. 2001. 71p. Tese (Doutorado) - Escola Superior de Agricultura Luiz de Queiroz, Piracicaba.

CORTEZ, J.G. Melhoramento da qualidade do café: influência de sistemas de produção e processamento sobre algumas características da bebida. 1996. 57p. Dissertação (Mestrado) - Universidade Estadual de Campinas, Campinas.

DENTAN, E. Café riotés: étude microscopique du processus d'infection. In: COLLOQUE SCIENTIFIQUE INTERNATIONAL SUR LE CAFÉ, 13., 1989, Paipa. Annales. Paris: Association Scientifique Internationale du Café, 1989a. p.127-144.

DENTAN, E. Étude microscopique de quelques types de café défectueux: grains noir, blanchâtres, cireux et "ardidos". In: COLLOQUE SCIENTIFIQUE INTERNATIONAL SUR LE CAFÉ, 13., 1989, Paipa. Annales. Paris: Association Scientifique Internationale du Café, 1989b. p.283-301.

DENTAN, E. Étude microscopique de quelques types de café défectueux II: grains à goût d'herbe, de terre, de moisi; grains puants, endommagés par de insectes. In: COLLOQUE SCIENTIFIQUE INTERNATIONAL SUR LE CAFÉ, 14., 1991, San Francisco. Annales. Paris: Association Scientifique Internationale du Café, 1992. p.293-311.

DENTAN, E. Examen microscopique de grains de café riotés. In: COLLOQUE SCIENTIFIQUE INTERNATIONAL SUR LE CAFÉ, 12., 1987, Montreux. Annales. Paris: Association Scientifique Internationale du Café, 1988. p.335-352.

FERIA-MORALES, A. The research and test unit of the International Coffee Organization Scientific activities focusing on the quality of coffee. In: COLLOQUE SCIENTIFIQUE INTERNATIONAL SUR LE CAFÉ, 13., 1989, Paipa. Annales. Paris: Association Scientifique Internationale du Café, 1989. p.159-180.

HEYDECKER, W. Vigour. In: ROBERTS, E.H. (Ed.). Viability of seeds. London: Chapman and Hall, 1974. p.209-252.

INSTITUTO BRASILEIRO DO CAFÉ (Rio de Janeiro, RJ). Classificação do café: noções gerais. Rio de Janeiro, 1985. 117p.

JONES, K.L.; JONES, S.E. Fermentations involved in the production of cocoa, coffee and tea. In: BUSHELL, M.E. (Ed.). Progress in industrial microbiology: modern applications of traditional biotechnologies. New York: Elsevier, 1984. p.433-458.

KRUG, H.P. Café duros. Revista do Instituto do Café, v.26, p.636638, 1940a.

KRUG, H.P. Café duros - II: um estudo sobre a qualidade dos cafés de varrição. Revista do Instituto do Café, v.27, p.1393-1396, 1940 b.

LIN, S.S. Efeito do período de armazenamento na lixiviação eletrolítica dos solutos celulares e qualidade fisiológica da semente de milho (Zea mays L.) e feijão (Phaseolus vulgaris L.). Revista Brasileira de Sementes, v.10, p.59-67, 1988.

LUCCA FILHO, O.A. Metodologia dos testes de sanidade de sementes. In: SOAVE, J.; WETZEL, M.M.V. da S. (Ed.). Patologia de sementes. Campinas: Fundação Cargill, 1987. p.276-298.

MARCOS FILHO, J.; AMORIN, H.V.; SILVAROLLA, M.B.; PESCARIN, H.M.C. Relações entre germinação, vigor e permeabilidade das membranas celulares durante a maturação de sementes de soja. In: SEMINÁRIO NACIONAL DE PESQUISA DE SOJA, 2., 1981, Brasília. Anais. Londrina: Embrapa-CNPSo, 1982. v.1, p.676-688.

MARCOS FILHO, J.; SILVA, W.R. da; NOVEMBRE, A.D.C.; CHAMMA, H.M.C.P. Estudo comparativo de métodos para a avaliação da qualidade fisiológica de sementes de soja, com ênfase ao teste de condutividade elétrica. Pesquisa Agropecuária Brasileira, v.25, p.1805-1815, 1990.

POPINIGIS, F. Fisiologia da semente. Brasília: Agiplan, 1977. 289p. PRETE, C.E.C. Condutividade elétrica do exsudato de grãos de café (Coffea arabica $\mathbf{L}$.) e sua relação com a qualidade de bebida. 1992. 125p. Tese (Doutorado) - Escola Superior de Agricultura Luiz de Queiroz, Piracicaba.

SCHOETTLE, A.W.; LEOPOLD, A.C. Solute leakage from artificially aged soybean seeds after imbibition. Crop Science, v.24, p. 835838,1984 .

TOLEDO, J.L.B.; BARBOSA, A.T. Classificação e degustação de café. Brasília: Sebrae; Associação Brasileira da Indústria do Café, 1998. 95p. (Série Negócios).

VANOS, V. Preliminary microbial ecological studies en "Rio taste" coffee beans. In: COLLOQUE SCIENTIFIQUE INTERNATIONAL SUR LE CAFÉ, 12., 1987, Montreux. Annales. Paris: Association Scientifique Internationale du Café, 1988. p.353-376.

WOODSTOCK, L.W. Physiological and biochemical tests for seed vigor. Seed Science \& Technology, v.1, p.127-157, 1973.

Recebido em 8 de julho de 2003 e aprovado em 26 de novembro de 2003. 